\title{
Effect of Ball to Powder Weight Ratio on the Mechanochemical Synthesis of $\mathrm{MoSi}_{2}$-TiC Nanocomposite Powder
}

\author{
Mohamad Zakeri ${ }^{\mathrm{a} *}$, Mohammad Ramezani ${ }^{\mathrm{b}}$, Ali Nazaric \\ ${ }^{a}$ Ceramic Department, Materials and Energy Research Center, P.O. Box 31787/316, Karaj, Iran \\ ${ }^{\mathrm{b}}$ Young Researchers Club, Saveh Branch, Islamic Azad University, Saveh, Iran \\ 'Department of Materials, Saveh Branch, Islamic Azad University, Saveh, Iran
}

Received: December 10, 2011; Revised: May 29, 2012

\begin{abstract}
$\mathrm{MoSi}_{2}-\mathrm{TiC}$ nanocomposite powders were successfully synthesized with different ball to powder weight ratios (BPR) by ball milling of $\mathrm{Mo}, \mathrm{Si}$, Ti and graphite elemental powders. Formation of this composite was studied by X-ray diffraction (XRD). Morphology and microstructure of the milled powders were monitored by scanning and transmission electron microscopy (SEM and TEM), respectively. There was incomplete formation in BPR 5:1 after 30 hours of milling, however, the formation of this composite was completed after 10 hours in BPRs 15:1 and 20:1. Higher BPRs with longer milling time led to partially transformation of $\beta$ to $\alpha \mathrm{MoSi}_{2}$. Based on Rietveld refinement analysis, and subsequent verification by TEM image, nanostructure powders with the mean grain size less than $25 \mathrm{~nm}$ were obtained in all BPRs. Very fine submicron powders in agglomerated ones for BPRs 10:1 and 15:1were obtained at the end of milling.
\end{abstract}

Keywords: $\mathrm{MoSi}_{2}-\mathrm{TiC}$, ball milling, nanostructure

\section{Introduction}

With the rapid development of aerospace technology, it is urgent to study the new material used in high temperature structural components. $\mathrm{MoSi}_{2}$ intermetallic compound has become an attractive candidate for structural application at temperatures up to $1600{ }^{\circ} \mathrm{C}$ because of its interesting combination of thermo-physical and mechanical properties ${ }^{1,2}$ such as high strength, ductility and oxidation resistance. Because of its relatively high conductivity, $\mathrm{MoSi}_{2}$ and $\mathrm{MoSi}_{2}$-based materials can be electro-discharge machined. However, it exhibits ceramic-like brittleness at room and metal-like plasticity at elevated temperatures.

The major problem impeding the use of $\mathrm{MoSi}_{2}$ as a high temperature structural material is its brittleness at low temperatures and low strength and creep resistance at temperatures above $1200{ }^{\circ} \mathrm{C}$. An effective method to solve both of these problems is the addition of brittle or ductile reinforcements as second phase in $\mathrm{MoSi}_{2}$ matrix. $\mathrm{MoSi}_{2}$ is thermodynamically stable with a wide variety of potential ceramic reinforcements for composites, including $\mathrm{SiC}, \mathrm{Si}_{3} \mathrm{~N}_{4}, \mathrm{ZrO}_{2}, \mathrm{Al}_{2} \mathrm{O}_{3}, \mathrm{TiB}_{2}, \mathrm{TiC}$ etc. Its stability extends essentially to the full range of important structural ceramic materials $^{3-10}$. TiC is another probable reinforcement for $\mathrm{MoSi}_{2}$ with potential advantages: (1) it has a brittle-to-ductile transition above $600{ }^{\circ} \mathrm{C}$, (2) the thermal expansion coefficient of $\mathrm{TiC}$ is virtually same as that of $\mathrm{MoSi}_{2}$, and (3) thermodynamic calculations indicate that $\mathrm{TiC}$ and $\mathrm{MoSi}_{2}$ should not react at the temperatures used for densification of $\mathrm{MoSi}_{2}{ }^{[11]}$. Preparation in nanostructure condition is another approach to improve mechanical properties ${ }^{12}$.

*e-mail: m_zakeri@merc.ac.ir
$\mathrm{MoSi}_{2}$-TiC composite can be produced easily by direct mixing of $\mathrm{MoSi}_{2}$ and $\mathrm{TiC}$ powders. But the resulting heterogeneous microstructure and high cost of the starting materials are two important drawbacks of this method ${ }^{13-17}$. Alternatively, $\mathrm{MoSi}_{2}$-TiC nanocomposite powder can be synthesized in situ through high energy reactive milling of a mixture of Mo, $\mathrm{Si}$, Ti and graphite powders. The formation of compounds via solid-state reaction that occurs during ball milling, called mechanical alloying (MA), is a promising way of producing such composites. During MA, both matrix and reinforcement are formed through in situ process, which will promote suitable bonding between matrix and reinforcement. Moreover, a homogeneous distribution of fine reinforcing particles can be obtained by the MA process ${ }^{18-20}$. There is no report on the synthesis of this composite except of our previous work. In that work $\mathrm{MoSi}_{2}-30$ wt. (\%) TiC nanocomposite powder was successfully synthesized by ball milling and following heat treatment. Results showed that the synthesis of this composite begins after 10 hours of milling and progresses gradually up to 30 hours of milling. $\mathrm{MoSi}_{2}-\mathrm{TiC}$ composite was completely synthesized after annealing of 30 hours milled powder at $900{ }^{\circ} \mathrm{C}^{[21]}$. Effect of $\mathrm{BPR}$ on the mechanochemical synthesis was investigated in the other systems. For example $\mathrm{FeAl}-\mathrm{Al}_{2} \mathrm{O}_{3}$ composite was formed after 120,270 and 360 minutes of milling at the BPRs of 5:1, 10:1 and 15:1 respectively. It means that in the higher $\mathrm{BPR}$, the shorter milling time is required for the synthesis ${ }^{22}$.

The aim of this work is in situ synthesis of $\mathrm{MoSi}_{2}-\mathrm{TiC}$ nanocomposite powder by mechanical milling of the corresponding elemental powders with different BPRs. Formation of this composite has been studied by 
thermodynamic discussions and its microstructure has been investigated by Reitveld refinement analysis.

\section{Experimental Procedures}

MA experiments were performed in a planetary ball mill at approximately room temperature and cup of speed 750 rounds per minute (RPM). The four cup planetary ball mill of Retch Company was used for MA experiments. Pure Merck Mo (99.7 wt. (\%), $50 \mu \mathrm{m}), \mathrm{Si}$ (99.8 wt. (\%), $25 \mu \mathrm{m})$, Ti (99.0 wt. (\%), $30 \mu \mathrm{m})$ and graphite (99.3 wt. (\%), $10 \mu \mathrm{m})$ were mixed to give the desired $\mathrm{MoSi}_{2}-30$ wt. (\%) TiC composition. Four BPRs of 5:1, 10:1, 15:1 and 20:1 were used. A distribution of 20,15 and $10 \mathrm{~mm}$ stainless steel balls was used in MA experiments. In order to prevent excess agglomeration 1 wt. (\%) Stearic acid was added. The powders and balls were charged into a stainless steel cup $(250 \mathrm{~mL})$ in an Ar atmosphere. Samples were removed for analysis in a glove box under an Ar atmosphere by interrupting milling at various intervals.

XRD profiles were recorded on a Siemens diffractometer (30 kV and $25 \mathrm{~mA}$ ) with $\mathrm{Cu} \mathrm{K \alpha}$ radiation $\left(1.5404 \mathrm{~A}^{\circ}\right.$ ). The Recorded XRD patterns were used for calculation of crystallite size and strain. Mean grain size and microstrain were calculated on the basis of Rietveld refinement method by using of X'Pert high score plus software (developed by PANalytical BV Company, Almelo, the Netherlands, and version $2.2 \mathrm{~b}$ ). In this method, peak profile fitting, size broadening and strain broadening were calculated based on the following equations ${ }^{23}$.

$G_{i k}=\gamma \frac{C_{0}^{0.5}}{H_{k \pi}}\left[1+C_{0} X_{i k}^{2}\right]^{-1}+(1-\gamma) \frac{C_{1}^{0.5}}{H_{k \pi}^{0.5}} \exp \left[-C 1 X_{i k}^{2}\right]$

$\mathrm{H}_{\mathrm{k}}=\left(U \tan ^{2} \theta+V \tan \theta+W\right)^{0.5}$

$D_{i}=\left(\frac{180}{\pi}\right) \frac{\lambda}{\left(W_{i}-W_{s t d}\right)^{0.5}}$

$\eta_{i}=\frac{\left[\left(U_{i}-U_{s t d}\right)-\left(W_{i}-W_{s t d}\right)\right]^{0.5}}{\frac{1}{100}\left[\frac{180}{\pi}\right\rceil 4(2 \ln 2)^{0.5}}$

where $\mathrm{G}_{\mathrm{ik}}$ is Pseudo-Voigt function, $\mathrm{C}_{0}=2, \mathrm{C}_{1}=4 \ln 2, \mathrm{H}_{\mathrm{k}}$ is full width at half maximum of the $\mathrm{K}_{\mathrm{th}}$ brag reflection, $\gamma$ is shape parameter, $\mathrm{X}_{\mathrm{ik}}=\left(2 \theta_{\mathrm{i}}-2 \theta_{\mathrm{k}}\right) / \mathrm{H}_{\mathrm{k}} . \mathrm{D}_{\mathrm{i}}, \eta_{\mathrm{i}}, \lambda, \mathrm{U}$ and $\mathrm{W}$ are grain size function, strain function, wavelength, strain parameter and size parameter of peak profile, respectively. In the size and strain functions, $i$ and std are referred to analyzed and standard samples, correspondingly. In this project, a pure $\mathrm{MoSi}_{2}$ that annealed at $1500{ }^{\circ} \mathrm{C}$ for 10 hours was used as standard material for deconvolution of instrumental broadening.

Structural observations of milled powders were carried out with a Philips EM208 TEM operating at $200 \mathrm{kV}$. The powders were ultrasonically dispersed in methanol. One drop of this suspension was placed on a copper grid for TEM observation. The morphology and particle size of samples were examined by using a Philips (XL30) SEM operating at $30 \mathrm{kV}$. Iron contamination of milled powders was measured by inductivity coupled plasma (ICP) method.

\section{Results and Discussions}

\subsection{Synthesis}

Effect of BPR was studied on the formation of $\mathrm{MoSi}_{2}$-TiC composite powders. As received powders including the mixture of $\mathrm{Mo}, \mathrm{Si}, \mathrm{Ti}$ and graphite elemental powders were blended to give the desired $\mathrm{MoSi}_{2}-30 \mathrm{wt}$. (\%) TiC. Figure 1 shows the XRD patterns of 10 hours milled powders with different BPRs. There is no reaction in BPR 5:1 and the as-received materials reflections can be seen after 10 hours of milling. Graphite reflections were disappeared as a result of large mass absorption coefficient of Mo and $\mathrm{Ti}$ in comparison with graphite (Table 1). In fact, the absorption of graphite reflections by Mo and $\mathrm{Ti}$ was promoted by the intimate mixing and size decreasing in the early stage of milling ${ }^{24}$.

With increasing milling energy at BPR 10:1, a partially reaction was performed between the starting materials. However, the strong Mo peak can still be seen in the pattern of this sample. Higher milling energy in BPR 15:1, led to the full reaction and formation of $\beta-\mathrm{MoSi}_{2}$ and TiC. $\beta-\mathrm{MoSi}_{2}$ is high temperature polymorph (HTP) and is unstable during room temperature. In fact, high exothermic reactions take place and increase the temperature of the powder particles. This condition favors the formation of the high temperature phase $\left(\beta-\mathrm{MoSi}_{2}\right.$ is stable in the temperatures above $\left.1900{ }^{\circ} \mathrm{C}\right)^{1}$. Formation of HTP of $\mathrm{MoSi}_{2}$ can be explained as follow; it is now well recognized that the structure and constitution of advanced materials can be better controlled by processing them under non-equilibrium (or far-from-equilibrium) conditions. Amongst many processes, which are in commercial use,

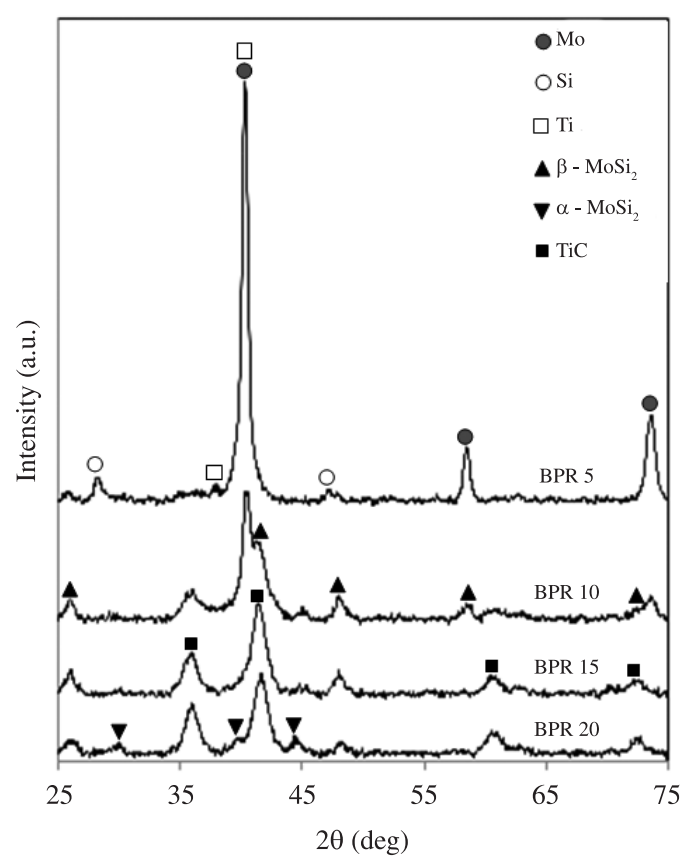

Figure 1. XRD patterns of the 10 hours milled powders with different BPRs. 
MA has been receiving serious attention from researchers. The central underlying technique is to synthesize materials in a non-equilibrium state by energizing and quenching. The energization involves bringing the material into a highly non-equilibrium (meta-stable) state by some external dynamical forcing, such as mechanical energy ${ }^{25}$. On the basis of above discussion, non-equilibrium condition of milling leads to the formation of HTP of $\mathrm{MoSi}_{2}$ that is unstable at room temperature. The synthesized $\beta-\mathrm{MoSi}_{2}$ was partially transformed to $\alpha-\mathrm{MoSi}_{2}$ at higher BPR (20:1).

As discussed in Figure 1, formation of $\mathrm{MoSi}_{2}-\mathrm{TiC}$ composite was completed after 10 hours milling in BPRs 15:1 and 20:1. Two samples with shorter milling times
(3.5 and 7 hours) was studied for the determining the exact formation time of this composite. Figure 2 a shows there is no reaction in BPR 15:1 after 3.5 hours of milling. On the other hand, in BPR 20:1, some minor $\mathrm{MoSi}_{2}$ was formed at this stage of milling. Increasing milling time to 7 hours in BPR 15, led to the formation of $\mathrm{MoSi}_{2}$ in minor amount (Figure 2b). In the BPR 20:1, at this stage of milling, the intensity of Mo peak was significantly decreased due to the formation of $\beta-\mathrm{MoSi}_{2}$.

The BPRs 5:1 and 10:1 were compared at longer milling times (20 and 30 hours) due to their incomplete formation of $\mathrm{MoSi}_{2}$-TiC composite. Figure 3a shows some minor amount of starting materials was reacted to form $\mathrm{MoSi}_{2}$ after

Table 1. Mass absorption coefficients of starting materials and products ${ }^{22}$.

\begin{tabular}{ccccccc}
\hline Phase & Mo & Ti & Si & Graphite & MoSi $_{2}$ & TiC \\
\hline MAC $\left(\mathrm{cm}^{2} \cdot \mathrm{g}^{-1}\right)$ & 158.45 & 196.14 & 62.07 & 4.3 & 122.86 & 157.68 \\
\hline
\end{tabular}

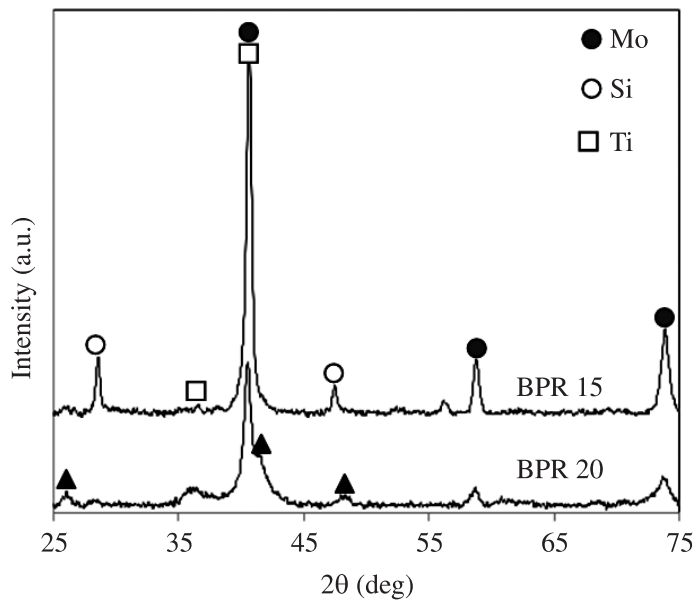

(a)

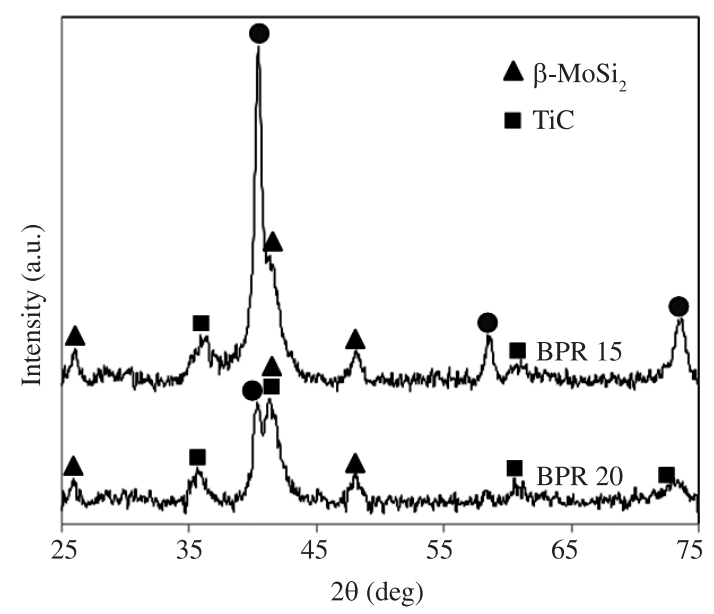

(b)

Figure 2. Effect of BPR on the formation of $\mathrm{MoSi}_{2}-\mathrm{TiC}$ nanocomposite powder after a) 3.5 hours and b) 7 hours of milling time.

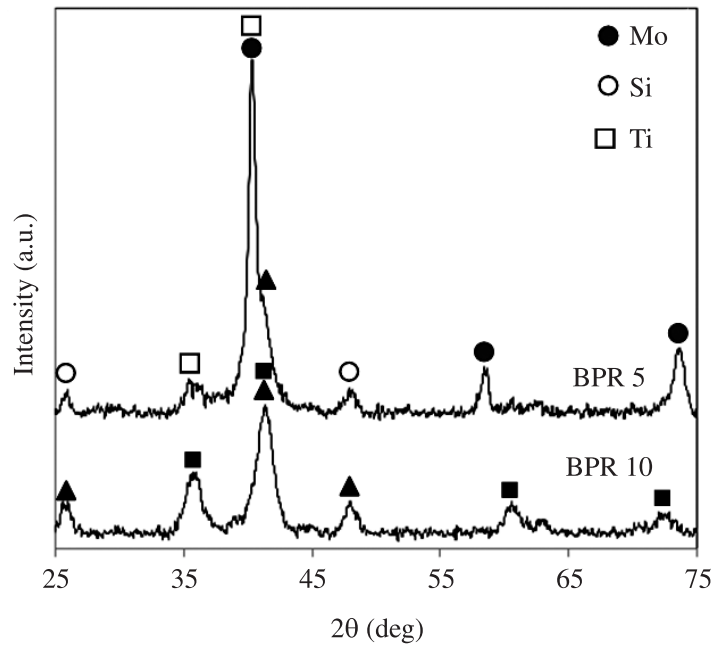

(a)

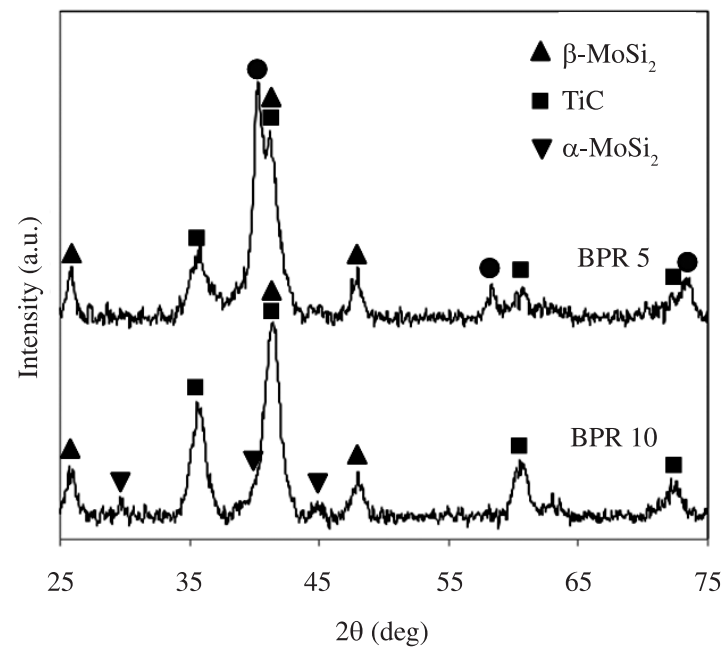

(b)

Figure 3. Effect of $\mathrm{BPR}$ on the formation of $\mathrm{MoSi}_{2}-\mathrm{TiC}$ nanocomposite powder after a) 20 hours and b) 30 hours of milling time. 
20 hours of milling in BPR 5:1. However, in BPR 10:1, the formation of this composite was completed at this stage of milling. Increasing milling time to 30 hours in BPR 5:1, resulted in the considerable formation of $\mathrm{MoSi}_{2}$ and $\mathrm{TiC}$ with the remaining of considerable amount of starting materials such as Mo. Longer milling time (30 hours) in BPR 10:1, had no considerable effect except partially transformation of $\beta-\mathrm{MoSi}_{2}$ to $\alpha-\mathrm{MoSi}_{2}$.

The beginning and completing time for the formation of $\mathrm{MoSi}_{2}$-TiC composite with the end product for all BPRs were summarized in Table 2. With increasing BPR, the beginning time was significantly decreased. Higher BPR led to the higher milling energy. It means that the activation energy for the formation of $\mathrm{MoSi}_{2}-\mathrm{TiC}$ composite is provided at the shorter milling time. . Higher milling energy also affect the completing time for the formation of this composite. Table 2 shows that the formation of this composite was not completed after 30 hours in BPR 5:1. However, in BPRs 15:1 and 20, this composite was formed after only 10 hours. It means that at higher BPRs, the higher energy per time is introduced to the milled powders. In the other words, the kinetic of $\mathrm{MoSi}_{2}-\mathrm{TiC}$ formation increases at higher BPRs. The long milling period for the formation of this composite at all BPRs indicates that it was performed in gradual mechanism. The longer milling time (10:1, 30 hours) or higher BPR (20:1, 10 hours) led to the partially transformation of $\beta-\mathrm{MoSi}_{2}$ to $\alpha-\mathrm{MoSi}_{2}$. It may be due to the activation of recovery mechanism or from the mechanical energy heating. Higher BPR with longer milling time led to the heating of milled powders from mechanical energy. Introducing of this energy to the milled powder promotes the transformation of meta-stable $\beta-\mathrm{MoSi}_{2}$ to stable $\alpha-\mathrm{MoSi}_{2}$.

\subsection{Morphology and Microstructure}

Figure 4 shows the morphology and particles size of 30 hours milled powders for all BPRs. In BPR 5:1, very small submicron particles with spherical morphology were obtained after 30 hours of milling (Figure 4a). A few small agglomerated particles can be seen in this sample. Higher BPR (10:1) led to the excessive agglomeration because of

Table 2. effect of BPR on the beginning and completing time of $\mathrm{MoSi}_{2}-\mathrm{TiC}$ formation.

\begin{tabular}{lcccc}
\hline \multicolumn{1}{c}{ BPR } & $\mathbf{5 : 1}$ & $\mathbf{1 0 : 1}$ & $\mathbf{1 5 : 1}$ & $\mathbf{2 0 : 1}$ \\
\hline Beginning time (hours) & 20 & 10 & 7 & 3.5 \\
Completing time (hours) & Incomplete at 30 hours & 20 & 10 & 10 \\
End product & $\beta-\mathrm{MoSi}_{2}, \mathrm{TiC}$ & $\beta-\mathrm{MoSi}_{2}, \alpha-\mathrm{MoSi}_{2}, \mathrm{TiC}$ & $\beta-\mathrm{MoSi}_{2}, \mathrm{TiC}$ & $\beta-\mathrm{MoSi}_{2}, \alpha-\mathrm{MoSi}_{2}, \mathrm{TiC}$ \\
\hline
\end{tabular}

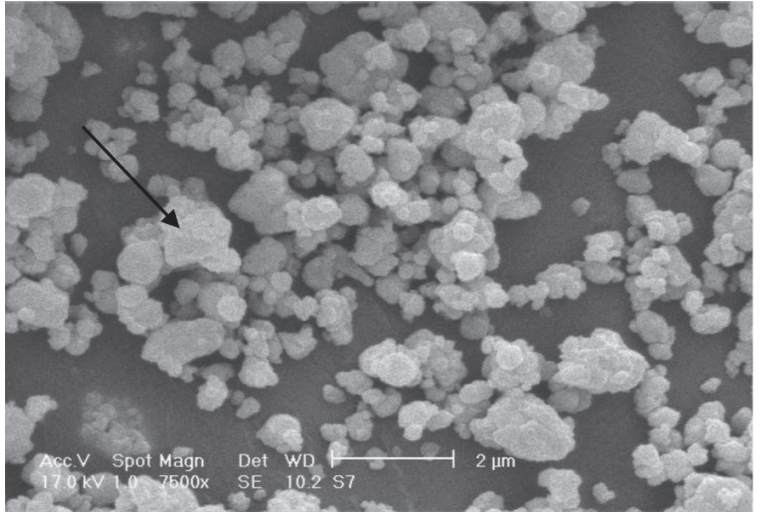

(a)

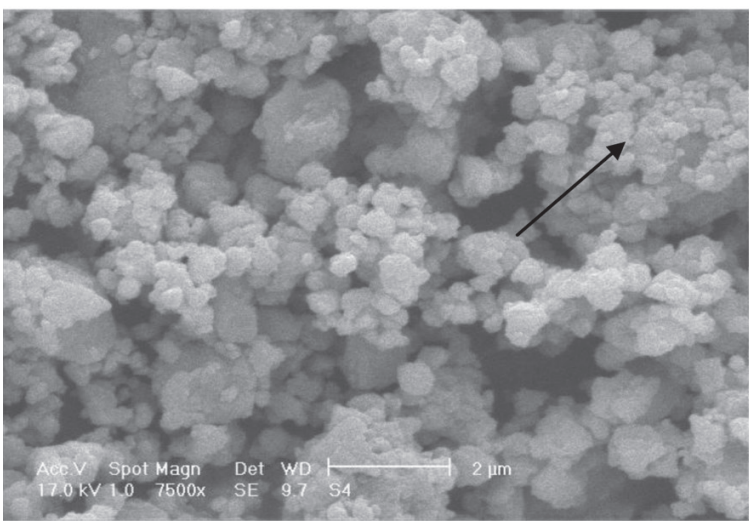

(c)

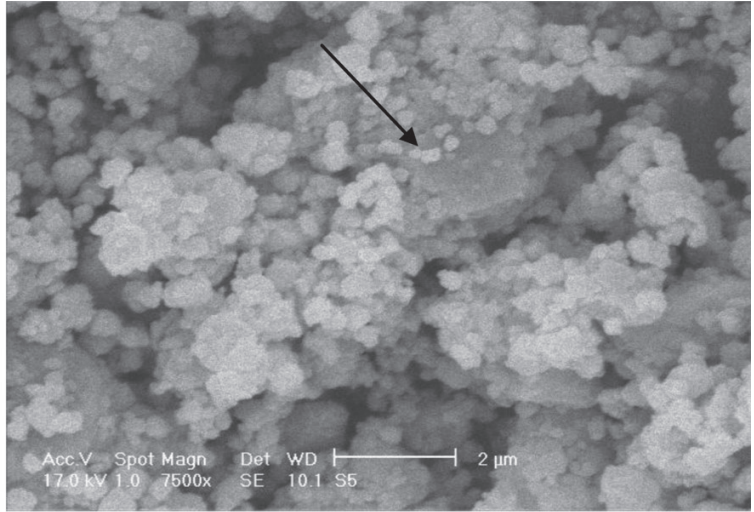

(b)

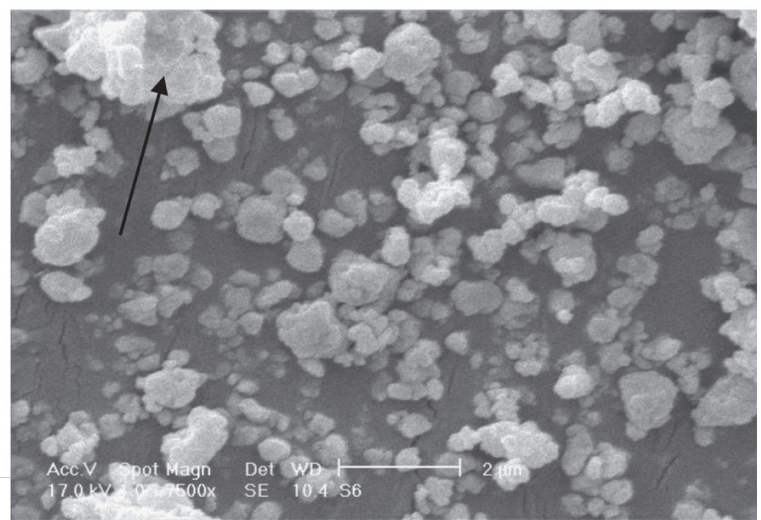

(d)

Figure 4. SEM images of 30 hours milled powder with the BPR of a) 5:1, b) 10:1, c) 15:1 and d) 20:1. 
higher milling energy. Cold welding and particles fracturing are in competition during milling process. For preventing excess agglomeration, Stearic acid was used as process control agent (PCA). In the lower BPR (5:1), the used PCA acts as surfactant and decreases the cold welding and agglomeration process. At higher BPR (10:1), the added PCA is decomposed due to the formation of $\mathrm{MoSi}_{2}-\mathrm{TiC}$ composite and its heat releasing. Therefore, there is no inhibitor for cold welding. All of primary particles were agglomerated at this BPR (Figure 4b). With increasing milling energy at higher BPR (15:1), cold working resulted in work hardening and fracturing of milled powders. Figure 4c shows that the amount and size of agglomerates were significantly decreased. These phenomena continue at higher BPR (20:1), so few agglomerates can be seen in this sample (Figure 4d).

Compositions of the milled powders were analyzed by energy dispersive spectroscopy (EDS) that was performed on the marked particles in Figure 4. The results of these analyses were presented in Figure 5. In all BPRs, there are $\mathrm{Mo}, \mathrm{Si}$ and $\mathrm{Ti}$ peaks that confirm the composition of $\mathrm{MoSi}_{2}$ and TiC. As expected, carbon cannot be detected by this method. There is another peak that attributed to $\mathrm{Fe}$ in all BPRs. This peak intensity, increases at higher BPRs. Fore confirming the existence of Fe peak, the Fe amount of 30 hours milled powders was measured by ICP method. The results of this measurement were presented in top right corner of each BPR in Figure 5. As seen, the Fe

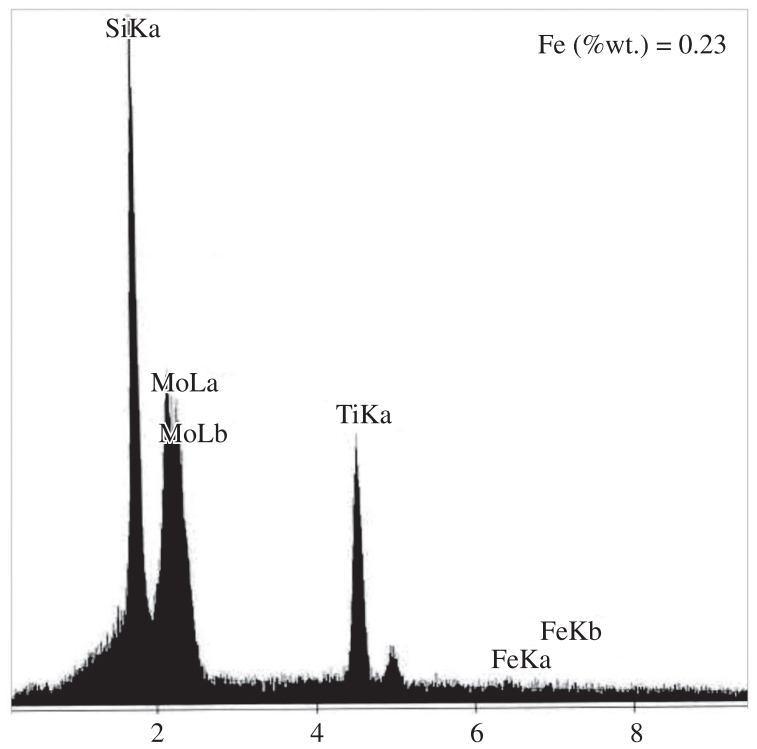

(a)

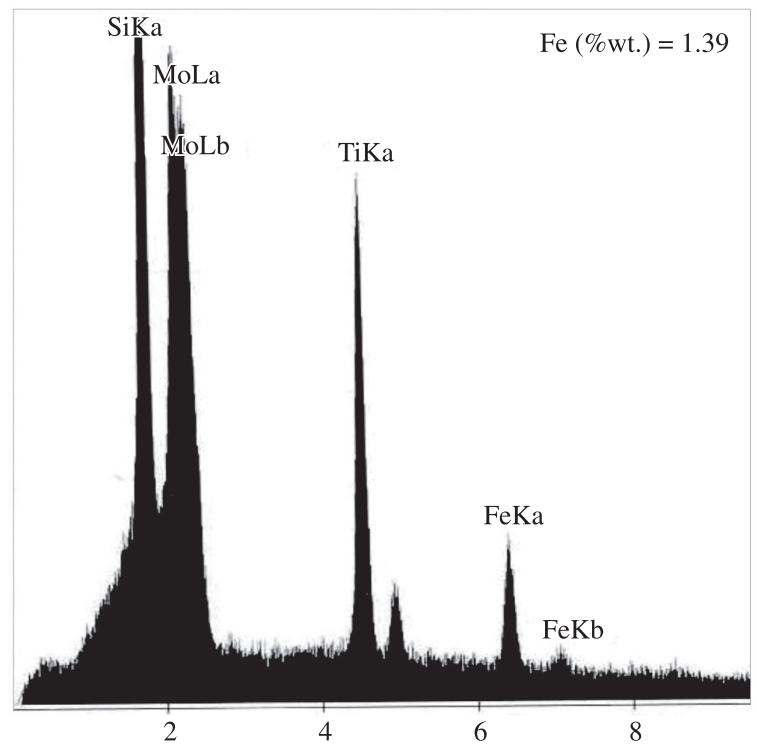

(c)

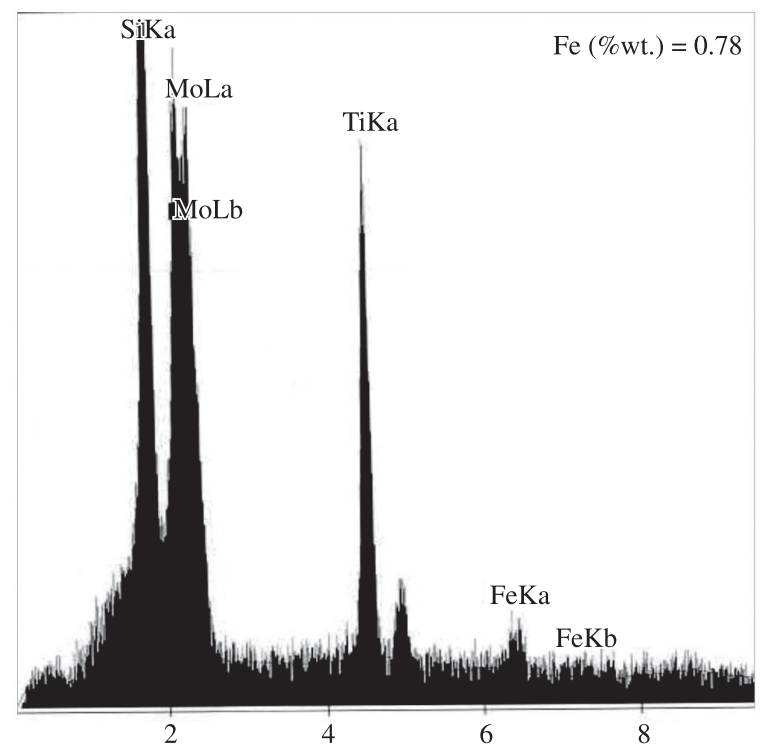

(b)

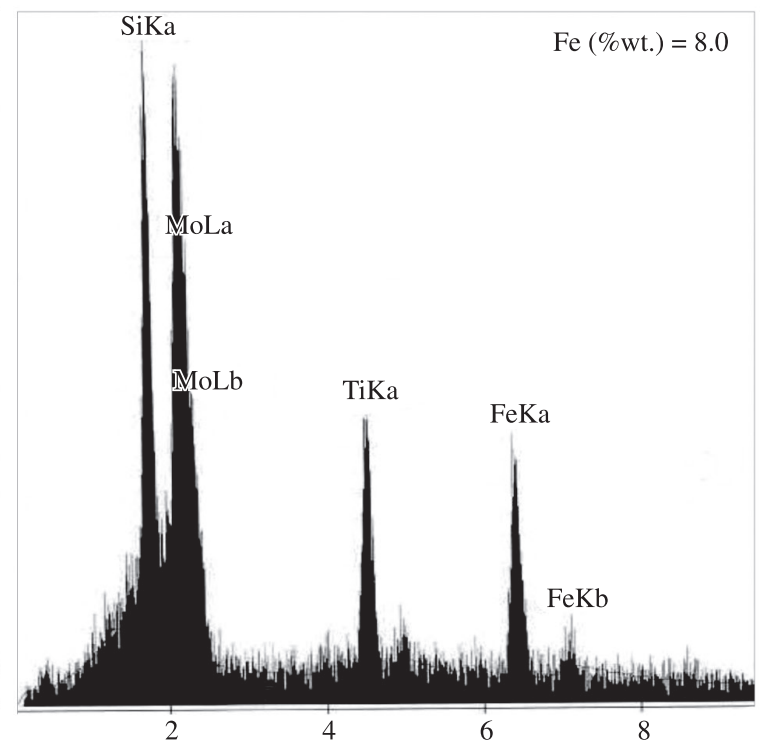

(d)

Figure 5. EDS analysis of the marked particles in Figure 4 at the BPRs of a) 5:1, b) 10:1, c) 15:1 and d) 20:1. 


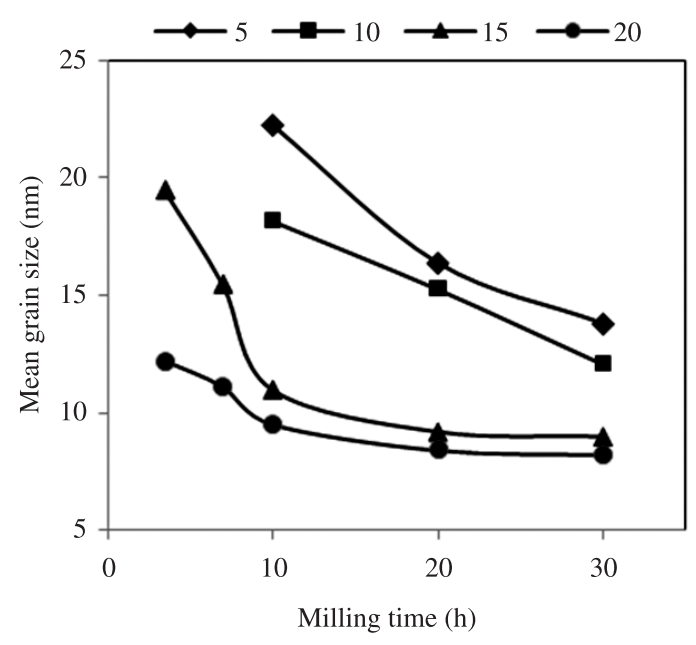

(a)

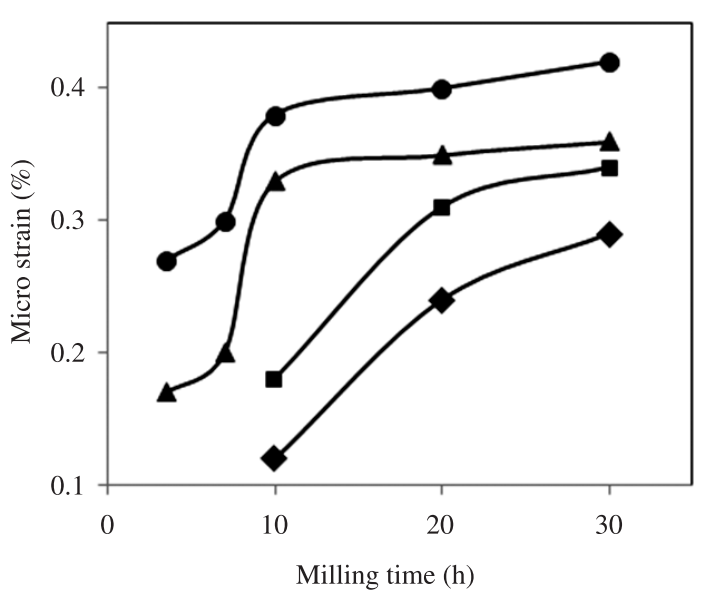

(b)

Figure 6. Mean grain size and microstrain of milled powders for all BPRs that were calculated on the basis of Rietveld refinement method.

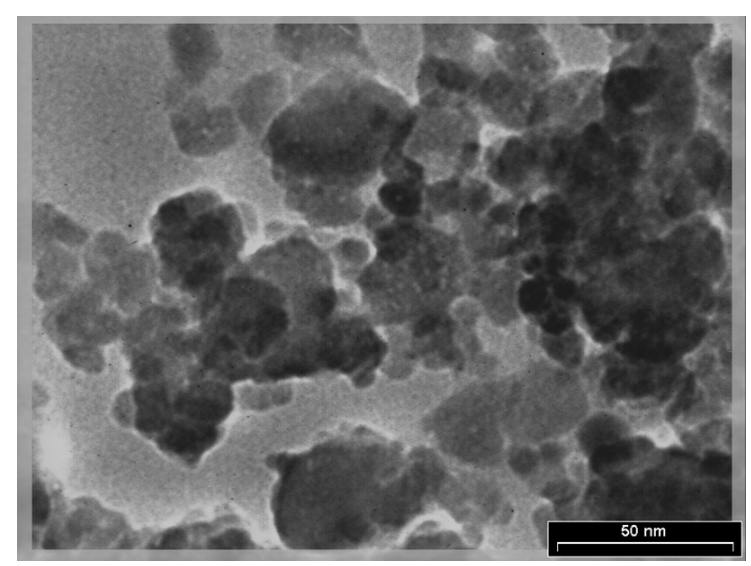

Figure 7. Bright field TEM image of 30 hours milled powder With the BPR of 10:1.

content increases from the minimum value of $0.23 \mathrm{wt}$. (\%) in BPR 5:1 to 8 wt. (\%) in BPR 20:1. These results indicate that the higher milling energy led to the higher wearing rate of steel cup and balls. In lower BPRs, this Fe impurity can be neglected due to its minor amount while in higher BPR; it can be removed by conventional leaching methods.

The mean grain size and microstrain of the milled powders were calculated on the basis of Reitveld refinement method (Figure 6). Longer milling time as well as higher BPRs led to the smaller mean grain size (Figure 6a). On the other hands, the milled powders with larger micro strain were obtained at higher BPRs and longer milling times (Figure 6b). As seen in both parameters, a steady state condition was obtained at longer milling time. It means that there is equilibrium between the grain size lessening and recovery mechanisms at longer milling times. In all BPRs and milling times, a nanostructure powders was obtained. The minimum mean grain size acquired for 30 hours-milled powder with 20:1 BPR. The bright field TEM image of 30 hours-milled sample with BPR of 10:1 was shown in Figure 7 due to the complete formation of $\mathrm{MoSi}_{2}$-TiC with the lower Fe impurity. A mean grain size of $12 \mathrm{~nm}$ was obtained for this sample by Rietveld method. Figure 7 shows that it is approximately in consistent with the Rietveld result.

\section{Conclusions}

In this research, the effect of the BPR was studied on the formation of $\mathrm{MoSi}_{2}-\mathrm{TiC}$ composite powder. Beginning and completing time for the formation of this composite were decreased with increasing BPR. High temperature polymorph of $\mathrm{MoSi}_{2}(\beta)$ was obtained at higher BPR or longer milling time. The minimum and maximum Fe impurity of 0.23 and $8 \mathrm{wt}$. (\%) were introduced to the 30 hours milled powders with the BPRs of 5:1 and 20:1, respectively. Nanostructure powders with the mean grain size less than $25 \mathrm{~nm}$ were obtained in all BPRs that confirmed by TEM image. 


\section{References}

1. Schlichting J. Molybdenum disilicide as a component of modern high temperature composites. High Temp-High Pressures. 1978; 10(3):241-269.

2. Meschter PJ and Schwartz DS. Silicide-matrix materials for high temperature applications. JOM. 1989; 10(1):52-59. http:// dx.doi.org/10.1007/BF03220384

3. Jeng YL and Lavernia EJ. Processing of molybdenum disilicide. Journal of Materials Science. 1994; 29 (1):2557-2571. http:// dx.doi.org/10.1007/BF00356804

4. Ward CM. Intermetallic-matrix composites. Intermetallics. 1994; 4(2):217.

5. Yang JM, Kai W and Jeng SM. Development of TiC particle-reinforced $\mathrm{MoSi}_{2}$ composite. Scripta Metallurgica. 1989;23(11):1953. http://dx.doi.org/10.1016/00369748(89)90489-4

6. Petrovic JJ.Toughening strategies for $\mathrm{MoSi}_{2}$-based hightemperature structural silicides. Intermetallics. 2000; 8(11):1175-1182. http:// dx.doi.org/10.1016/S0966-9795(00)00044-3

7. Soboyejo W, Brooks D, Chen LC and Lederich R. Transformation toughening and fracture behavior of molybdenum disilicide composites reinforced with partially stabilized zirconia. Journal of the American Ceramic Society. 1995; 78(1):1481. http://dx.doi.org/10.1111/j.1151-2916.1995.tb08841.x

8. Zakeri M, Yazdani-Rad R, Enayati MH and Rahimipoor MR. Synthesis of $\mathrm{MoSi}_{2}-\mathrm{Al}_{2} \mathrm{O}_{3}$ nanocomposite by mechanical alloying. Materials Science and Engineering: A. 2006; 430(2):185-188. http://dx.doi.org/10.1016/j. msea.2006.05.112

9. Yazdani-rad R, Mirvakili SA and Zakeri M. Synthesis of $\left(\mathrm{Mo}_{1-\mathrm{x}} \mathrm{Cr}_{\mathrm{x}}\right) \mathrm{Si}_{2}$ nanostructured powders via mechanical alloying and following heat treatment. Journal of Alloys and Compounds. 2010; 489(1):379-383. http://dx.doi. org/10.1016/j.jallcom.2009.09.089

10. Zakeri $\mathrm{M}$ and Ahmadi M. Effect of starting composition on the formation of $\mathrm{MoSi}_{2}-\mathrm{SiC}$ nanocomposite powder via ball milling. Bulletin of Materials Science, 2011. In press.

11. Vasudevan A and Petrovic JJ. A comparative overview of molybdenum disilicide composites. Materials Science and Engineering: A. 1995: 155(1):1.

12. Takacs L. Combustion Phenomena Induced by Ball Milling. Materials Science Forum, 1998; 269-272(1):513-523. http:// dx.doi.org/10.4028/www.scientific.net/MSF.269-272.513
13. Sun L and Pan J. Fabrication and characterization of TiC-particle-reinforced $\mathrm{MoSi}_{2}$ composites. Journal of the European Ceramic Society. 2002; 22(2):791-796. http://dx.doi. org/10.1016/S0955-2219(01)00378-8

14. Sun L and Pan J. TiC whisker-reinforced $\mathrm{MoSi}_{2}$ matrix composites. Materials Letters. 2001; 51(1):270-274. http:// dx.doi.org/10.1016/S0167-577X(01)00303-2

15. Yuping $\mathrm{Z}, \mathrm{Xu} \mathrm{C}$ and Watanabe T. The effects of carbon addition on the mechanical properties of $\mathrm{MoSi}_{2}$-TiC composites. Ceramics International. 2002; 28(1):387-392. http://dx.doi. org/10.1016/S0272-8842(01)00106-7

16. Menga J, Lua J, Wang J and Yang S. Preparation and properties of $\mathrm{MoSi}_{2}$ composites reinforced by $\mathrm{TiC}, \mathrm{TiCN}$, and $\mathrm{TiB}_{2}$. Materials Science and Engineering: A. 2005; 396(1):277-284.

17. Sun L, Pan J and Lin C. Wear behavior of TiC-MoSi composites. Materials Letters. 2003; 57(1):1239- 1243. http:// dx.doi.org/10.1016/S0167-577X(02)00965-5

18. Koch CC. Structural nanocrystalline materials. Journal of Materials Science. 2007; 42(1):1403-14. http://dx.doi. org/10.1007/s10853-006-0609-3

19. Koch CC. Intermetallic matrix composites prepared by mechanical alloying. Materials Science and Engineering: A. 1998; 244(1):39-48. http://dx.doi.org/10.1016/S09215093(97)00824-1

20. El-Eskandarany MS. Mechanical alloying for fabrication of advanced engineering materials. New York: Noyes Publication; 2001. http://dx.doi.org/10.1016/B978-0815514626.50005-6

21. Zakeri M and Ramezani M. Synthesis of $\mathrm{MoSi}_{2}-\mathrm{TiC}$ nanocomposite powder via mechanical alloying and subsequent annealing. Ceramics International. 2012; 38(1):1353-1357. http://dx.doi.org/10.1016/j.ceramint.2011.09.012

22. Zakeri M, Rahimipour $M$ and Pourhosseini J. In situ formation of $\mathrm{FeAl}-\mathrm{Al}_{2} \mathrm{O}_{3}$ nanocomposite at different conditions of milling and subsequent annealing. Powder Metallurgy. 2011; 54(3):292-298. http://dx.doi.org/10.1179/ 003258909X12502679013738

23. Rietveld HM. A profile refinement method for nuclear and magnetic structures. Journal of Applied Crystallography. 1969; 2(1):65-71. http://dx.doi.org/10.1107/ S0021889869006558

24. Cullity BD. Elements of X-Ray Diffraction. 2nd ed. AddisonWesley Publishing; 1977.

25. Suryanarayana C. Non-equilibrium Processing of Materials. Oxford: Pergamon Press; 1999. 